\title{
Consenso | Protocolo Brasileiro para Infecções Sexualmente Transmissíveis 2020: sífilis adquirida
}

doi: 10.1590/S1679-4974202100004.esp1

\author{
Brazilian Protocol for Sexually Transmitted Infections 2020: acquired syphilis
}

Protocolo Brasileño para Infecciones de Transmisión Sexual 2020: sífilis adquirida

\author{
Francisca Lidiane Sampaio Freitas ${ }^{1}$ - (1) orcid.org/0000-0003-1344-6389 \\ Adele Schwartz Benzaken ${ }^{2}$ - (1) orcid.org/0000-0002-1656-5749 \\ Mauro Romero Leal de Passos ${ }^{3}$ - (1) orcid.org/0000-0002-6183-7985 \\ Ivo Castelo Branco Coelho4 - (1) orcid.org/0000-0002-2238-0388 \\ Angélica Espinosa Miranda' - (1) orcid.org/0000-0002-5556-8379 \\ 'Ministério da Saúde, Secretaria de Vigilância em Saúde, Brasília, DF, Brasil \\ ${ }^{2}$ Fundação de Medicina Tropical Doutor Heitor Vieira Dourado, Manaus, AM, Brasil \\ ${ }^{3}$ Universidade Federal Fluminense, Centro de Ciências Médicas, Niterói, RJ, Brasil \\ ${ }^{4}$ Universidade Federal do Ceará, Faculdade de Medicina, Fortaleza, CE, Brasil
}

\section{Resumo}

0 Protocolo Clínico e Diretrizes Terapêuticas para Atenção Integral às Pessoas com Infecções Sexualmente Transmissíveis, publicado pelo Ministério da Saúde do Brasil em 2020, contempla a atualização sobre sífilis adquirida. 0 documento apresenta a utilização de testes rápidos, a segurança e a eficácia da administração da benzilpenicilina benzatina, o seguimento dos casos, o manejo clínico e laboratorial da neurossífilis, a abordagem de parcerias sexuais, a assistência e o acompanhamento de gestantes diagnosticadas e as especificidades da coinfecção sífilis e HIV, além de uma síntese sobre a notificação dos casos. É necessário capacitar gestores e profissionais de saúde de forma contínua, com vistas à integração entre assistência e vigilância, ao fortalecimento de ações efetivas de controle da sífilis, à abrangência da busca de parcerias sexuais e ao amplo acesso de populações mais vulneráveis aos serviços de saúde.

Palavras-chave: Sífilis; Protocolos clínicos; Diagnóstico; Terapêutica.

Endereço para correspondência:

Francisca Lidiane Sampaio Freitas - Ministério da Saúde, Secretaria de Vigilância em Saúde, SRTVN Quadra 701, Via W 5 Norte, Lote D, Edifício PO 700, Brasília, DF, Brasil. CEP: 70719-040

E-mail: lidianesfreitas18@gmail.com 


\section{Apresentação}

0 presente artigo resume o capítulo sobre sífilis adquirida que integra o Protocolo Clínico e Diretrizes Terapêuticas (PCDT) para Atenção Integral às Pessoas com Infecções Sexualmente Transmissíveis (IST), aprovado pela Comissão Nacional de Incorporação de Tecnologias no Sistema Único de Saúde (Conitec), por meio da Portaria ${ }^{0} 42$, de 5 de outubro de 2018. ${ }^{1}$ Para a elaboração do conteúdo, foram selecionadas evidências disponíveis na literatura para análise e discussão entre especialistas. 0 PCDT foi atualizado pelo grupo técnico e publicado em 2020 pela Secretaria de Vigilância em Saúde do Ministério da Saúde do Brasil.

\section{A maioria das pessoas com síflis é assintomática, o que contribui para manter a cadeia de transmissão. Sem o tratamento adequado da gestante com sífilis, consequências graves são esperadas, como abortamento, prematuridade, baixo peso ao nascer, natimortalidade e sífilis congênita.}

\section{Aspectos epidemiológicos}

A sífilis é uma IST causada pela bactéria Treponema pallidum, subespécie pallidum. A transmissão ocorre principalmente por via sexual (oral, vaginal ou anal). Pode ser transmitida também verticalmente, com uma taxa de mortalidade fetal superior a $40 \%{ }^{2}$

A maioria das pessoas com sífilis é assintomática, o que contribui para manter a cadeia de transmissão. Se não tratada, a doença pode evoluir para complicações sistêmicas graves, após vários anos da infecção inicial. ${ }^{3-5}$ Sem $o$ tratamento adequado da gestante com sífilis, consequências graves são esperadas no feto ou concepto, tais como abortamento, prematuridade, baixo peso ao nascer, natimortalidade e manifestações clínicas precoces ou tardias da sífilis congênita. ${ }^{6}$

Os treponemas penetram diretamente nas membranas mucosas ou entram por abrasões da pele. A transmissão é maior nos estágios iniciais (sífilis primária e secundária) da infecção, diminuindo gradativamente com 0 tempo. ${ }^{5}$
Em 2016, a Organização Mundial da Saúde (OMS) estimou 6,3 milhões de novos casos de sífilis no mundo, sendo a prevalência em homens e mulheres de $0,5 \%$, com valores regionais variando de $0,1 \%$ a $1,6 \% .^{7}$ № Brasil, estudo nacional ${ }^{8}$ de 2016 constatou prevalência de sífilis de $0,6 \%$ em jovens conscritos, que foram chamados para comissões de seleção, após a fase de alistamento militar. Prevalências altas de sífilis foram observadas entre segmentos das populações-chave no Brasil, como homens que fazem sexo com homens $(9,9 \%),{ }^{9}$ trabalhadoras do sexo $(8,5 \%)^{10}$ e pessoas privadas de liberdade $(3,8 \%){ }^{11}$

A taxa de detecção da sífilis adquirida aumentou de 59,1 casos por 100.000 habitantes, em 2017, para 75,8 casos por 100.000 habitantes, em 2018, sendo verificada maior tendência de crescimento na população entre 20 e 29 anos, de 2010 a 2018, segundo dados do Sistema de Informação de Agravos de Notificação (Sinan). ${ }^{12}$

\section{Aspectos clínicos}

Para orientar o tratamento e o seguimento clínico-laboratorial, a infecção sifilítica é dividida nos estágios sífilis recente (primária, secundária e latente recente) com um ano de evolução, e sífilis tardia (latente tardia e terciária), com mais de um ano. ${ }^{4}$

Os estágios clínicos da sífilis adquirida estão apresentados na Figura 1. Nas fases iniciais, a sintomatologia é variável e desaparece, independentemente de tratamento. As manifestações clínicas propiciam a suspeição clínica, mas não há sinal ou sintoma exclusivo, o que pode gerar confusão com outras patologias e dificultar o diagnóstico. ${ }^{13}$

0 acometimento do sistema nervoso central (SNC) pode ocorrer durante qualquer estágio clínico da sífilis. ${ }^{14}$ A neurossífilis precoce se manifesta logo após a infecção sifilítica, acompanhando-se de meningite e anormalidades nos nervos cranianos. ${ }^{15,16} \mathrm{Com}$ a era antibiótica e o uso dominante dos beta-lactâmicos, a apresentação clínica da neurossífilis sofreu mudanças, com aumento dos quadros oligossintomáticos e atípicos da doença. ${ }^{5}$

\section{Diagnóstico}

Para o diagnóstico de sífilis, é necessário combinar dados clínicos, resultados de testes diagnósticos, histórico de infecções anteriores e investigação de recente exposição sexual de risco. ${ }^{17} \mathrm{~A}$ análise da 


\begin{tabular}{|c|c|}
\hline Estágios & Manifestações clínicas \\
\hline \multirow[t]{2}{*}{ Primária } & $\begin{array}{l}\text { Cancro duro (úlcera genital) rico em treponemas, geralmente único e indolor, com borda bem definida e } \\
\text { regular, base endurecida e fundo limpo, localizado no local de entrada da bactéria (pênis, vulva, vagina, } \\
\text { colo uterino, ânus, boca, ou outros locais do tegumento) }\end{array}$ \\
\hline & Linfonodos regionais aumentados em tamanho e número \\
\hline \multirow{5}{*}{ Secundária } & $\begin{array}{l}\text { Lesões cutâneo-mucosas (roséola, placas mucosas, sifílides papulosas, sifilides palmoplantares, } \\
\text { condiloma plano, alopecia em clareira, madarose, rouquidão) }\end{array}$ \\
\hline & Micropoliadenopatia \\
\hline & Linfadenopatia generalizada \\
\hline & Sinais constitucionais \\
\hline & Quadros neurológicos, oculares, hepáticos \\
\hline Latente recente (até um ano de duração) & Assintomática \\
\hline Latente tardia (mais de um ano de duração & Assintomática \\
\hline \multirow{4}{*}{ Terciária } & Cutâneas: lesões gomosas e nodulares, de caráter destrutivo \\
\hline & Ósseas: periostite, osteíte gomosa ou esclerosante, artrites, sinovites e nódulos justa-articulares \\
\hline & $\begin{array}{l}\text { Cardiovasculares: estenose de coronárias, aortite e aneurisma da aorta, especialmente } \\
\text { da porção torácica }\end{array}$ \\
\hline & $\begin{array}{l}\text { Neurológicas: meningite, gomas do cérebro ou da medula, atrofia do nervo óptico, lesão do sétimo par } \\
\text { craniano, manifestações psiquiátricas, tabes dorsalis e quadros demenciais, como } \\
\text { o da paralisia geral }\end{array}$ \\
\hline
\end{tabular}

Fonte: adaptado do Protocolo Clínico e Diretrizes Terapêuticas para Atenção Integral às Pessoas com Infecções Sexualmente Transmissíveis 2020.13

Figura 1 - Manifestações clínicas e estágios da sífilis adquirida

história sexual tem relevância para a elucidação diagnóstica, o que exige habilidade profissional e garantia de confidencialidade. ${ }^{18}$

Os exames diretos e os testes imunológicos são métodos utilizados para auxiliar no diagnóstico da sífilis. 0s exames diretos são aqueles em que se realiza a pesquisa ou detecção do T. pallidum em amostras biológicas, coletadas diretamente das lesões primárias e secundárias. ${ }^{19}$

Os testes imunológicos (treponêmicos e não treponêmicos) são os mais comuns na prática clínica para rastreamento de pessoas assintomáticas e diagnóstico de sintomáticas. ${ }^{5}$ Caracterizam-se pela pesquisa de anticorpos totais em amostras de sangue total, soro ou plasma (Figura 2). Embora ocorra a síntese de anticorpos IgM específicos na fase inicial da infecção, esses anticorpos também são encontrados durante o estágio tardio da infecção; portanto, testes que detectam somente IgM não são recomendados., ${ }^{2,17}$

Os testes treponêmicos detectam anticorpos específicos produzidos contra os antígenos de T. pallidum. Como exemplo, destaca-se o teste rápido (imunocromatográfico), que não necessita de estrutura laboratorial. Em aproximadamente $85 \%$ dos casos, os testes treponêmicos permanecem reagentes por toda a vida (cicatriz sorológica), independentemente de tratamento, ${ }^{19} 0$ que não permite diferenciar infecção ativa de infecção passada. ${ }^{5}$

0s testes não treponêmicos, como o venereal disease research laboratory (VDRL), detectam anticorpos anticardiolipina não específicos para os antígenos do T. pallidum. ${ }^{19}$ Caracterizam-se por serem testes semiquantitativos, pois, nos casos de resultado reagente, realiza-se a diluição da amostra para titulação desses anticorpos. ${ }^{2}$ Tal titulação pode variar, dependendo do estágio da doença e da realização ou não do tratamento. Títulos baixos $(<1: 4)$ de anticorpos não treponêmicos podem ser encontrados em fases recentes e tardias da infecção, persistindo por meses ou anos. Por isso, não há um ponto de corte específico, devendo qualquer titulação ser investigada como caso de sífilis. ${ }^{13}$ Chama-se cicatriz sorológica a não negativação dos testes não treponêmicos após o tratamento. Esse evento pode ser temporário ou 


\begin{tabular}{|c|c|c|}
\hline Testes imunológicos & Tipos & Observações \\
\hline \multirow{4}{*}{ Treponêmicos } & Teste rápido (ex.: imunocromatográficos) & \multirow{4}{*}{$\begin{array}{l}\text { São os primeiros a se tornarem reagentes. } \\
\text { Permanecem reagentes na maioria dos casos de } \\
\text { sífilis durante toda a vida, independentemente do } \\
\text { tratamento. } \\
\text { São importantes para diagnóstico, mas não estão } \\
\text { indicados para o monitoramento da resposta ao } \\
\text { tratamento. }\end{array}$} \\
\hline & $\begin{array}{l}\text { Teste de imunofluorescência indireta - fluorescent } \\
\text { treponemal antibody-absorption (FTA-Abs) }\end{array}$ & \\
\hline & $\begin{array}{l}\text { Ensaios imunoenzimáticos - enzyme-linked } \\
\text { immunossorbent assay (ELISA) e suas variações, como } \\
\text { os ensaios de quimioluminescência }\end{array}$ & \\
\hline & $\begin{array}{l}\text { Testes de hemaglutinação - Treponema Pallidum } \\
\text { Haemagglutination Test (TPHA) e de aglutinação de } \\
\text { partículas - T. pallidum particle agglutination assay } \\
\text { (TPPA); ensaios de micro-hemaglutinação - micro- } \\
\text { haemagglutination assay (MHA-TP) }\end{array}$ & \\
\hline \multirow{4}{*}{ Não treponêmicos } & Venereal disease research laboratory (VDRL) & \multirow{4}{*}{$\begin{array}{l}\text { Tornam-se reagentes cerca de uma a três semanas } \\
\text { após } 0 \text { aparecimento do cancro duro. } \\
0 \text { resultado final desses testes reagentes deve ser } \\
\text { expresso em títulos, conforme a última diluição que } \\
\text { apresentar reatividade (1:2, 1:4, 1:8 etc.). } \\
\text { São importantes para diagnóstico e monitoramento } \\
\text { da resposta ao tratamento. }\end{array}$} \\
\hline & Rapid plasma reagin (RPR) & \\
\hline & Toluidine red unheated serum test (TRUST) & \\
\hline & Unheated-serum reagin (USR) & \\
\hline
\end{tabular}

Fonte: adaptado do Protocolo Clínico e Diretrizes Terapêuticas para Atenção Integral às Pessoas com Infecções Sexualmente Transmissíveis 2020.13

Figura 2 - Testes imunológicos para diagnóstico de sífilis

persistente, e apresentar desde títulos baixos até elevados, a depender do título inicial encontrado no momento do diagnóstico. ${ }^{4,17}$

Recomenda-se iniciar a investigação por um teste treponêmico, de preferência o teste rápido, devido à sua maior sensibilidade. ${ }^{2,17}$ Diante do resultado, existem diferentes combinações de utilização de testes treponêmicos e não treponêmicos, com possíveis interpretações e respectivas condutas (Figura 3). ${ }^{13,17}$

Os profissionais de saúde, especialmente de medicina e enfermagem, devem explicitar a finalidade dos testes imunológicos no formulário de solicitação à rede laboratorial. Na abordagem diagnóstica, são consideradas três situações diferentes: 0 diagnóstico de sífilis, quando não se dispõe do teste rápido no serviço de saúde; o diagnóstico de sífilis, após teste rápido reagente no local da consulta; e o seguimento do tratamento, quando o diagnóstico e o tratamento foram realizados, sendo necessário monitorar os títulos dos anticorpos não treponêmicos para controle de cura, preferencialmente com o mesmo método utilizado no diagnóstico. ${ }^{13}$

Não existe teste padrão ouro para diagnóstico de neurossífilis. Este baseia-se na combinação de achados clínicos, alterações do líquido cefalorraquidiano
(LCR) e resultado de teste não treponêmico no LCR. É raro encontrar pessoas com neurossífilis que não apresentem pleocitose. ${ }^{20}$ Embora níveis de proteína no LCR não sejam nem sensíveis nem específicos para 0 diagnóstico de neurossífilis, a normalização proteica é importante para o monitoramento pós-tratamento..$^{21-24}$

\section{Tratamento}

Recomenda-se tratamento imediato, com benzilpenicilina benzatina, após um teste - treponêmico ou não treponêmico - reagente para sífilis nas seguintes situações, independentemente da presença de sinais e sintomas: ${ }^{13}$ gestantes; vítimas de violência sexual; pessoas com chance de perda de seguimento (que não retornarão ao serviço); pessoas com sinais e sintomas de sífilis primária ou secundária; e pessoas sem diagnóstico prévio de sífilis.

0 tratamento após 0 primeiro teste reagente não exclui a necessidade de realização do segundo teste, do seguimento clínico-laboratorial e do diagnóstico e tratamento das parcerias sexuais. Há esquemas terapêuticos específicos conforme a classificação clínica da sífilis (Figura 4). ${ }^{13}$ A resolução dos sinais e sintomas após o tratamento indica resposta à terapia. 


\begin{tabular}{|c|c|c|c|}
\hline $\begin{array}{l}\text { Primeiro teste }{ }^{a}+\text { teste } \\
\text { complementar }\end{array}$ & \multicolumn{2}{|l|}{ Possíveis interpretações } & Conduta \\
\hline \multirow{2}{*}{$\begin{array}{l}\text { Teste treponêmico reagente + teste } \\
\text { não treponêmico reagente ou Teste } \\
\text { não treponêmico reagente + teste } \\
\text { treponêmico reagente }\end{array}$} & - Diagnóstico de sífilis & $\begin{array}{l}\text { - Classificação do estágio clínico a ser } \\
\text { definida de acordo com o tempo de } \\
\text { infecção e o histórico de tratamento. }\end{array}$ & \multirow{6}{*}{$\begin{array}{l}\text { - Quando for sífilis, tratar, realizar } \\
\text { monitoramento com teste não } \\
\text { treponêmico e notificar o caso de } \\
\text { sífilis. } \\
\text { - Quando for confirmado caso de } \\
\text { cicatriz sorológica, apenas orientar. } \\
\text { - Para os casos concluídos como } \\
\text { ausência de sífilis, apenas orientar. }\end{array}$} \\
\hline & \multicolumn{2}{|l|}{ - Cicatriz sorológicab } & \\
\hline \multirow{4}{*}{$\begin{array}{l}\text { Teste não treponêmico reagente + } \\
\text { teste treponêmico não reagente ou } \\
\text { Teste treponêmico reagente + teste } \\
\text { não treponêmico não reagente }\end{array}$} & \multirow{2}{*}{$\begin{array}{l}\text { - Realiza-se um terceiro } \\
\text { teste treponêmico com } \\
\text { metodologia diferente do } \\
\text { treponêmico realizado. }\end{array}$} & $\begin{array}{l}\text { - Se reagente: diagnóstico de sífilis ou } \\
\text { cicatriz sorológica. }\end{array}$ & \\
\hline & & $\begin{array}{l}\text { - Se não reagente: considera-se } \\
\text { resultado falso reagente para o } \\
\text { primeiro teste, sendo excluído } 0 \\
\text { diagnóstico de sífilis. }\end{array}$ & \\
\hline & \multicolumn{2}{|c|}{$\begin{array}{l}\text { - Se o terceiro teste treponêmico não estiver disponível, avaliar } \\
\text { exposição de risco, sinais e sintomas e histórico de tratamento para } \\
\text { definição de conduta. }\end{array}$} & \\
\hline & \multicolumn{2}{|l|}{ - Cicatriz sorológicab } & \\
\hline $\begin{array}{l}\text { Teste não treponêmico ou treponêmico } \\
\text { não reagente + não realizar teste } \\
\text { complementar se o primeiro teste for } \\
\text { não reagente e se não houver suspeita } \\
\text { clínica de sífilis primária }\end{array}$ & \multicolumn{2}{|c|}{$\begin{array}{l}\text { - Ausência de infecção ou período de janela } \\
\text { imunológica' de sífilis recente. }\end{array}$} & $\begin{array}{l}\text { - Em caso de suspeita clínica e/ou } \\
\text { epidemiológica, solicitar nova coleta } \\
\text { de amostra em } 30 \text { dias. } \\
\text { - Evitar retardar a instituição do } \\
\text { tratamento, caso o diagnóstico } \\
\text { de sífilis seja o mais provável (ex.: } \\
\text { visualização de úlcera anogenital) ou o } \\
\text { retorno da pessoa ao serviço de saúde } \\
\text { não possa ser garantido. }\end{array}$ \\
\hline
\end{tabular}

Fonte: adaptado do Protocolo Clínico e Diretrizes Terapêuticas para Atenção Integral às Pessoas com Infecções Sexualmente Transmissíveis 2020.13

Notas: a) Recomenda-se tratamento imediato com benzilpenicilina benzatina após apenas um teste reagente de sífilis (teste treponêmico ou não treponêmico) nas situações descritas no item "Tratamento", sem excluir a necessidade de realização do segundo teste para definição do diagnóstico; b) Tratamento anterior documentado com queda da titulação em pelo menos duas diluições; c) Janela imunológica: período entre a infecção e a produção suficiente de anticorpos para serem detectados por testes imunológicos.

\section{Figura 3 - Resultados de testes treponêmicos e não treponêmicos, interpretação e conduta}

Deve ser realizado o monitoramento pós-tratamento com teste não treponêmico para determinar a resposta imunológica adequada. ${ }^{25}$

Para assegurar a disponibilidade da benzilpenicilina benzatina, esta passou a ser adquirida de forma centralizada pelo Ministério da Saúde, como componente estratégico da assistência farmacêutica na Relação Nacional de Medicamentos Essenciais, a partir de $2017 .{ }^{26}$ Os casos notificados de sífilis (adquirida e em gestantes) subsidiam a base de cálculo para compra e distribuição. ${ }^{13}$

A benzilpenicilina benzatina deve ser administrada por via intramuscular (IM). ${ }^{19}$ A região ventro-glútea é o local preferencial, por ser livre de vasos e nervos importantes e constituir tecido subcutâneo de menor espessura, o que implica poucos efeitos adversos e menor dor local. ${ }^{27}$ A região do vasto lateral da coxa e 0 dorso glúteo são outras opões para aplicação. Quando é inviável a aplicação pela via IM nos locais indicados devido à presença de silicone (prótese ou silicone líquido industrial), recomenda-se 0 tratamento alternativo por via oral (Figura 4). ${ }^{13}$

A reação de Jarisch-Herxheimer é um episódio que pode acontecer nas primeiras 24 horas após 0 início do tratamento com penicilina, principalmente na sífilis primária e secundária. Manifesta-se por meio de exacerbação das lesões cutâneas, com eritema, dor ou prurido, mal-estar geral, febre, cefaleia e artralgia. ${ }^{28}$ Os antipiréticos podem ser utilizados para controlar os sintomas, porém não há comprovação de prevenção da reação. ${ }^{4}$ As pessoas devem ser alertadas quanto à possibilidade de ocorrência desse evento benigno $\mathrm{e}$ autolimitado, ${ }^{29} \mathrm{e}$, especialmente, sobre a distinção em relação aos quadros de alergia à penicilina. ${ }^{30}$ 


\begin{tabular}{|c|c|c|c|}
\hline Classificação clínica & Esquema terapêutico & $\begin{array}{l}\text { Alternativa }{ }^{a} \text { (exceto para } \\
\text { gestantes) }\end{array}$ & Seguimento \\
\hline $\begin{array}{l}\text { Sífilis recente: sífilis primária, } \\
\text { secundária e latente recente (com } \\
\text { até um ano de evolução) }\end{array}$ & $\begin{array}{l}\text { Benzilpenicilina benzatina } 2,4 \\
\text { milhões de unidades internacionais } \\
\text { (UI), intramuscular (IM), dose única } \\
\text { (1,2 milhão em cada glúteo) }\end{array}$ & $\begin{array}{l}\text { Doxiciclina } 100 \mathrm{mg}, 12 / 12 \mathrm{~h} \text {, via oral } \\
\text { (V0), por } 15 \text { dias }\end{array}$ & $\begin{array}{l}\text { Teste não treponêmico trimestral } \\
\text { até } 12 \text { meses de acompanhamento } \\
\text { (em gestantes, o controle deve ser } \\
\text { mensal) }\end{array}$ \\
\hline \multirow[t]{2}{*}{$\begin{array}{l}\text { Sífilis tardia: sífilis latente tardia } \\
\text { (com mais de um ano de evolução) } \\
\text { ou latente com duração ignorada e } \\
\text { sífilis terciária }\end{array}$} & $\begin{array}{l}\text { Benzilpenicilina benzatina 2,4 } \\
\text { milhões de UI, IM, } 1 \text { vez/semana } \\
\text { (1,2 milhão em cada glúteo) por } 3 \\
\text { semanas }^{\text {b }}\end{array}$ & \multirow[t]{2}{*}{$\begin{array}{l}\text { Doxiciclina 100mg, 12/12h, V0, por } \\
30 \text { dias }\end{array}$} & \multirow[t]{2}{*}{$\begin{array}{l}\text { Teste não treponêmico trimestral } \\
\text { até } 12 \text { meses de acompanhamento } \\
\text { (em gestantes, o controle deve ser } \\
\text { mensal) }\end{array}$} \\
\hline & Dose total: 7,2 milhões & & \\
\hline Neurossífilis & $\begin{array}{l}\text { Benzilpenicilina potássica } \\
\text { (cristalina), } 3 \text { a } 4 \text { milhões de UI, } \\
\text { 4/4h, intravenosa (IV) ou por } \\
\text { infusão contínua, totalizando 18-24 } \\
\text { milhões por dia, por } 14 \text { dias }\end{array}$ & $\begin{array}{l}\text { Ceftriaxona 2g, IV, 1x/dia, por 10-14 } \\
\text { dias }\end{array}$ & $\begin{array}{l}\text { Exame de líquido cefalorraquidiano } \\
\text { de } 6 / 6 \text { meses até normalização }\end{array}$ \\
\hline
\end{tabular}

Fonte: adaptado do Protocolo Clínico e Diretrizes Terapêuticas para Atenção Integral às Pessoas com Infecções Sexualmente Transmissíveis 2020.13

Notas: a) A benzilpenicilina benzatina é a única opção segura e eficaz para o tratamento adequado das gestantes. Qualquer outro tratamento realizado durante a gestação, para fins de definição de caso e abordagem terapêutica de síilis congênita, é considerado tratamento não adequado da mãe; por conseguinte, o recém-nascido será notificado como sífilis congênita e submetido à avaliação clínica e laboratorial; b) 0 intervalo entre doses não deve ultrapassar 14 dias. Caso isso ocorra, 0 esquema deve ser reiniciado. ${ }^{19}$

\section{Figura 4 - Tratamento e seguimento de casos de sífilis e neurossífilis}

0 risco de anafilaxia da utilização de benzilpenicilina benzatina foi $0,002 \%$, esperando-se de 0 a 3 casos de anafilaxia por 100.000 pacientes tratados, segundo revisão sistemática com metanálise de 13 estudos. $\mathrm{Na}$ população de gestantes, não houve reação anafilática ou morte devido ao uso da benzilpenicilina benzatina em 1.244 mulheres, com um caso de rash cutâneo relatado. ${ }^{31}$

A adrenalina é o medicamento de escolha para tratamento da reação anafilática. Caso esta ocorra, devem-se seguir recomendações do protocolo da atenção primária à saúde em relação ao atendimento à demanda espontânea e urgências e emergências. ${ }^{32}$

0 receio de profissionais de saúde relacionado às reações adversas decorrentes da penicilina, sobretudo à raríssima reação anafilática, contribui para a perda do momento oportuno de tratamento de pessoas com sífilis; além disso, mantém a cadeia de transmissão da infecção e a ocorrência de sífilis congênita. ${ }^{13}$ Profissionais de enfermagem estão respaldados pelo Conselho Federal de Enfermagem para ampla administração da benzilpenicilina benzatina na atenção primária. ${ }^{33,34}$

Estima-se que $80 \%$ a $90 \%$ dos autorrelatos de alergia à penicilina são considerados equivocados, na sua maioria em decorrência da dificuldade em diferenciar 0 que é reação ou sintoma da doença. ${ }^{35}$ Algumas situações isoladamente não configuram alergia, como sintomas gastrointestinais, cefaleia, prurido, história familiar e reações suspeitas há mais de dez anos. A história clínica deve ser minuciosa para a estratificação de risco de alergia à penicilina, bem como para a obtenção adequada das informações e definição da conduta correta. Dessa forma, evitam-se encaminhamentos desnecessários para dessensibilização em ambiente hospitalar. ${ }^{36}$

0 monitoramento da resposta ao tratamento é mandatório e deve ser realizado em toda a rede de atenção ambulatorial à saúde. A avaliação do declínio dos marcadores de resposta imunológica ao T. pallidum utiliza como parâmetro o teste não treponêmico não reagente ou a queda na titulação em, pelo menos, duas diluições em até seis meses para sífilis recente e queda na titulação em, pelo menos, duas diluições em até 12 meses para sífilis tardia. ${ }^{4,37-40}$

Quanto mais precoce for o diagnóstico e o tratamento, mais rapidamente anticorpos circulantes desaparecerão, ocorrendo a negativação dos testes não treponêmicos, ou, ainda, a estabilização destes em títulos baixos. 0 registro da titulação do teste não treponêmico no início do tratamento serve como base para o monitoramento clínico-laboratorial. ${ }^{17}$

São critérios de retratamento com benzilpenicilina benzatina: ${ }^{13}$ ausência de redução da titulação em duas diluições no intervalo de seis meses (sífilis recente) ou 
12 meses (sífilis tardia) após o tratamento adequado (ex.: de 1:32 para 1:8), ou aumento da titulação em duas diluições ou mais (ex.: de 1:16 para 1:64), ou persistência ou recorrência de sinais e sintomas clínicos.

Em casos de reinfecção, recomenda-se a investigação de neurossífilis por meio de punção lombar na população geral, quando não houver exposição sexual de risco. Para pessoas vivendo com HIV (PVHIV), a investigação está indicada em todos os casos de retratamento, independentemente de ter ocorrido ou não nova exposição. Após o tratamento adequado, quando descartada nova exposição sexual de risco durante 0 período analisado, a persistência de resultados reagentes em testes não treponêmicos, com queda prévia da titulação em pelo menos duas diluições, é denominada de cicatriz sorológica e não caracteriza falha terapêutica. ${ }^{13}$

Para neurossífilis, devem ser tratadas todas as pessoas que apresentem VDRL reagente no LCR, independentemente da presença de sinais e sintomas neurológicos ou oculares, ou VDRL não reagente no LCR, mas com alterações bioquímicas no LCR e presença de sinais e sintomas neurológicos ou oculares ou alterações de imagem do SNC característicos da doença, e desde que essas alterações não possam ser explicadas por outra doença. 0s pacientes com exame inicial negativo no LCR também devem ser submetidos à punção de líquor de controle após seis meses do término do tratamento (Figura 4). ${ }^{13}$

Na persistência de alterações do LCR, é indicado retratamento com benzilpenicilina benzatina. Em amostras de sangue, a queda da titulação de testes não treponêmicos em pelo menos duas diluições ou sororreversão para não reagente pode ser um parâmetro a ser considerado como resposta ao tratamento da neurossífilis, principalmente em um contexto de punção lombar indisponível. ${ }^{41}$

\section{Vigilância, prevenção e controle}

A sífilis adquirida é de notificação compulsória no Brasil desde 2010, conforme a Portaria de Consolidação $\mathrm{n}^{0}$ 4, de 28 de setembro de $2017 .^{42}$ Tal notificação é obrigatória para médicos, demais profissionais de saúde ou responsáveis pelos serviços de saúde públicos e privados que prestam assistência ao paciente. ${ }^{43}$ Assim, reforça-se a necessidade da notificação oportuna de todos os casos ao Sinan, de forma a subsidiar a formulação e implementação de políticas públicas em IST no país.

Estima-se que $46 \%$ a $60 \%$ das parcerias sexuais de pessoas com sífilis (primária e secundária) estejam infectadas. ${ }^{44}$ Se houver exposição recente (em até 90 dias), mesmo que a pessoa apresente testes imunológicos não reagentes, ${ }^{4}$ recomenda-se tratamento presuntivo com dose única de benzilpenicilina benzatina 2,4 milhões de unidades internacionais (UI), IM (1,2 milhão de UI em cada glúteo). Salienta-se que a avaliação clínica e o seguimento laboratorial são indispensáveis. ${ }^{13} \mathrm{~A}$ abordagem dos contatos sexuais contribui para diminuir a carga da infecção na comunidade, rastrear pessoas assintomáticas e identificar redes de risco sexual. ${ }^{45}$

Para o seguimento clínico-laboratorial das pessoas com sífilis adquirida, a titulação do teste não treponêmico deve ser realizada a cada três meses até $012^{\circ}$ mês do acompanhamento (3, 6, 9 e 12 meses). Esse monitoramento contribui para classificar a resposta ao tratamento, identificar possível reinfecção e estabelecer a conduta adequada para cada caso. ${ }^{13}$

$\mathrm{Na}$ maioria das rotinas laboratoriais, os testes não treponêmicos não são automatizados, o que pode causar diferença entre leituras, quando métodos distintos são utilizados ou realizados por mais de um observador. Por isso, variações do título em uma diluição (ex.: de 1:16 para 1:8) não possuem significado clínico. Recomenda-se que o seguimento seja realizado, sempre que possível, com o mesmo método utilizado no diagnóstico. ${ }^{17}$

No capítulo de sífilis adquirida do PCDT consta uma seção sobre o algoritmo de decisão clínica para manejo da sífilis (adquirida e em gestantes), com a síntese das recomendações para rastreamento, diagnóstico, tratamento, notificação e monitoramento clínico-laboratorial dos casos. ${ }^{13}$

\section{Populações e situações especiais}

\section{Gestantes}

As gestantes devem ser testadas para sífilis na primeira consulta de pré-natal (idealmente no primeiro trimestre), no início do terceiro trimestre e na internação para o parto, em caso de abortamento, ou natimortalidade, ou história de exposição de risco, ou violência sexual. 0 monitoramento clínico-laboratorial com teste não treponêmico deve ser 
mensal durante a gestação. ${ }^{46}$ Após o parto, esse seguimento é trimestral até $012^{\circ}$ mês de acompanhamento. ${ }^{13}$

É indispensável garantir diagnóstico e tratamento de gestantes e parcerias sexuais, além de realizar 0 registro dos procedimentos na caderneta de pré-natal. Tais condutas contribuem para impedir que o recémnascido seja submetido a intervenções biomédicas desnecessárias. ${ }^{46}$ Também é importante estimular a participação de pai ou parceria durante todo 0 processo de pré-natal, para o fortalecimento de vínculos afetivos saudáveis. ${ }^{47}$

\section{Infecção pelo HIV}

Para todas as PVHIV diagnosticadas com sífilis, em caso de sinais ou sintomas oculares ou neurológicos, a consulta com especialistas deve ser precoce e a punção lombar é imposição diagnóstica. As recomendações para a realização de punção lombar em PVHIV a fim de investigar neurossífilis abrangem presença de sintomas neurológicos ou oftalmológicos, evidências de sífilis terciária ativa e falha do tratamento clínico, independentemente da história sexual..$^{13}$

$\mathrm{Na}$ infecção por HIV, as manifestações clínicas da sífilis e a resposta terapêutica podem ser distintas devido à imunidade de cada pessoa. Destacam-se presença de múltiplos cancros, maior frequência das lesões secundárias e reação de Jarisch-Herxheimer. ${ }^{48,49}$ os critérios de diagnóstico e tratamento de sífilis para
PVHIV são os mesmos utilizados para pessoas sem infecção pelo HIV. ${ }^{4}$

A atualização do capítulo de sífilis adquirida do PCDT converge com a necessidade de capacitar gestores e profissionais de saúde de forma contínua, com vistas à integração entre assistência e vigilância, ao fortalecimento de ações efetivas de prevenção, ao rastreamento de pessoas assintomáticas e ao diagnóstico, tratamento, acompanhamento e vigilância dos casos, além da abrangência da busca de parcerias sexuais e do amplo acesso de populações mais vulneráveis aos serviços de saúde.

\section{Contribuição dos autores}

Freitas FLS, Miranda AE, Benzaken AS, Passos MRL e Coelho, IVB contribuíram com a concepção, delineamento do estudo, revisão bibliográfica, redação e revisão crítica do artigo. Todos os autores aprovaram a versão final e declararam-se responsáveis por todos os aspectos do trabalho, incluindo a garantia de sua precisão e integridade.

\section{Agradecimento}

Os autores agradecem aos membros do grupo técnico de especialistas responsáveis pela elaboração do PCDT para Atenção Integral às Pessoas com IST em 2020 pela contribuição substancial para a realização deste trabalho.

\section{Referências}

1. Brasil. Ministério da Saúde. Portaria MS/SCTIE $\mathrm{n}^{0} 42$, de 5 de outubro de 2018. Torna pública a decisão de aprovar o Protocolo Clínico e Diretrizes Terapêuticas para Atenção Integral às Pessoas com Infecções Sexualmente Transmissíveis (IST), no âmbito do Sistema Único de Saúde - SUS [Internet]. Diário Oficial da União, Brasília (DF), 2018 out 8 [citado 2020 out 15];Seção 1:88. Disponível em: http://bvsms.saude.gov.br/bvs/saudelegis/ sctie/2018/prt0042_08_10_2018.html

2. Lasagabaster MA, Guerra LO. Syphilis. Enferm Infecc Microbiol Clin [Internet]. 2019 Jun-Jul [cited 2020 0ct 15];37(6):398-404. Available from: https://doi.org/10.1016/j.eimc.2018.12.009
3. Hook EW 3rd. Syphilis. Lancet. 2017 Apr 15;389(10078):1550-1557. Epub 2016 Dec 18. Erratum in: Lancet. 2019 Mar 9;393(10175):986. Available from: https://doi.org/10.1016/S0140-6736(16)32411-4

4. Workowski KA, Bolan GA; Centers for Disease Control and Prevention. Sexually transmitted diseases treatment guidelines, 2015. MMWR Recomm Rep [Internet]. 2015 Jun [cited 2020 0ct 15];64(RR03):1-137. Available from: https:/www.cdc.gov/ mmwr/preview/mmwrhtml/rr6403a1.htm

5. Peeling RW, Mabey D, Kamb ML, Chen X-S, Radolf JD, Benzaken AS. Syphilis. Nat Rev Dis Prim [Internet]. 2017 0ct [cited 2020 May 29];3:17073. Available from: http://www.nature.com/articles/nrdp201773 
6. Gomez GB, Kamb ML, Newman LM, Mark J, Broutet N, Hawkes SJ. Untreated maternal syphilis and adverse outcomes of pregnancy: a systematic review and meta-analysis. Bull World Health Organ [Internet]. 2013 [cited 2020 0ct 15];91(3):217-26. Available from: https://doi.org/10.2471/BLT.12.107623

7. Rowley J, Vander Hoorn S, Korenromp E, Low N, Unemo M, Abu-Raddad LJ, et al. Chlamydia, gonorrhoea, trichomoniasis and syphilis: global prevalence and incidence estimates, 2016. Bull World Health Organ [Internet]. 2019 Aug [cited 2020 0ct 15];97(8):548-62. Available from: https://dx.doi.org/10.2471\%2FBLT.18.228486

8. Motta LR, Sperhacke RD, Adami AG, Kato SK, Vanni AC, Paganella MP, et al. Syphilis prevalence and risk factors among young men presenting to the Brazilian Army in 2016: Results from a national survey. Medicine (Baltimore) [Internet]. 2018 Nov [cited 2020 0ct 15];97(47):e:13309. Available from: https://doi.org/10.1097/md.0000000000013309

9. Cunha CB, Friedman RK, de Boni RB, Gaydos C, Guimarães MR, Siqueira BH, et al. Chlamydia trachomatis, Neisseria gonorrhoeae and syphilis among men who have sex with men in Brazil. BMC Public Health [Internet]. 2015 Jul [cited 2020 0ct 15];15:686. Available from: https://doi.org/10.1186/s12889-015-2002-0

10. Ferreira-Júnior ODC, Guimarães MDC, Damacena GN, Almeida WS, Souza-Júnior PRB, Szwarcwald CL, et al. Prevalence estimates of HIV, syphilis, hepatitis $\mathrm{B}$ and $\mathrm{C}$ among female sex workers (FSW) in Brazil, 2016. Medicine (Baltimore) [Internet]. 2018 May [cited 2020 0ct 15];97(1S Suppl 1):S3-8. Available from: https://doi.org/10.1097/md.0000000000009218

11. Correa ME, Croda J, Castro ARCM, Oliveira SMVL, Pompilio MA, Souza R0, et al. High Prevalence of Treponema pallidum Infection in Brazilian Prisoners. Am J Trop Med Hyg [Internet]. 2017 Oct [cited 2020 0ct 15];97(4):1078-84. Available from: https://doi.org/10.4269/ajtmh.17-0098

12. Ministério da Saúde (BR). Secretaria de Vigilância em Saúde. Departamento de Doenças de Condições Crônicas e Infecções Sexualmente Transmissíveis. Sífilis | 2019. Bol Epidemiol [Internet]. 2019 out [citado 2020 out 15];especial. Disponível em: http://www.aids.gov.br/ pt-br/pub/2019/boletim-epidemiologico-sifilis-2019v

13. Ministério da Saúde (BR). Secretaria de Vigilância em Saúde. Departamento de Doenças de Condições Crônicas e Infecções Sexualmente Transmissíveis. Protocolo clínico e diretrizes terapêuticas para atenção integral às pessoas com infecções sexualmente transmissíveis (IST) [Internet]. Brasília: Ministério da Saúde; 2015 [citado 2020 out 15]. 248 p. Disponível em: http:/www.aids.gov.br/pt-br/ pub/2015/protocolo-clinico-e-diretrizes-terapeuticas-para-atencao-integral-pessoas-com-infeccoes

14. Marra CM. Neurosyphilis. Continuum (Minneap Minn) [Internet]. 2015 Dec [cited 2020 Oct 15];21(6):1714-28. Available from: https:// doi.org/10.1212/con.0000000000000250v

15. Tuddenham S, Ghanem KG. Neurosyphilis: knowledge gaps and controversies. Sex Transm Dis [Internet]. 2018 Mar [cited 2020 0ct 15];45(3):147-51. Available from: https://doi.org/10.1097/olq.0000000000000723

16. Musher DM. Editorial commentary: polymerase chain reaction for the tpp 47 gene: a new test for neurosyphilis. Clin Infect Dis [Internet]. 2016 Nov [cited 2020 0ct 15];63(9):1187-8. Available from: https://doi.org/10.1093/cid/ciw518

17. Ministério da Saúde (BR). Secretaria de Vigilância em Saúde. Departamento de Vigilância, Prevenção e Controle das Infecções Sexualmente Transmissíveis, do HIV/Aids e das Hepatites Virais. Manual técnico para diagnóstico da sífilis [Internet]. Brasília: Ministério da Saúde; 2016 [citado 2020 out 15]. Disponível em: http:/www.aids.gov.br/pt-br/pub/2016/ manual-tecnico-para-diagnostico-da-sifilis

18. Çakmak SK, Tamer E, Karadağ AS, Waugh M. Syphilis: a great imitator. Clin Dermatology [Internet]. 2019 May [cited 2020 0ct 15];37(3):182-91. Available from: https://doi.org/10.1016/j.clindermatol.2019.01.007

19. World Health Organization - WHO. WHO Guideline for the treatment of Treponema pallidum (syphilis) [Internet]. Genebra: World Health Organization; 2016 [cited 2020 Jun 6]. 60 p. Available from: http://apps.who.int/ iris/bitstream/10665/249572/1/9789241549806-eng.pdf

20. Marra CM, Maxwell CL, Dunaway SB, Sahi SK, Tantalo LC. Cerebrospinal fluid Treponema pallidum particle agglutination assay for neurosyphilis diagnosis. J Clin Microbiol [Internet]. 2017 Jun [cited 2020 0ct 15];55(6):1865-70. Available from: https://doi.org/10.1128/jcm.00310-17

21. Marra CM, Critchlow CW, Hook EW, Collier AC, Lukehart SA. Cerebrospinal fluid treponemal antibodies in untreated early syphilis. Arch Neurol [Internet]. 1995 Jan [cited 2020 0ct 15];52(1):68-72. Available from: https://doi.org/10.1001/archneur.1995.00540250072015 
22. Merritt HH, Adams RD, Solomon HC. Neurosyphilis. New York: Oxford University Press; 1946.

23. Hooshmand H, Escobar MR, Kopf SW. Neurosyphilis. A study of 241 patients. JAMA [Internet]. 1972 Feb [cited 2020 0ct 15];219(6):726-9. Available from: https://doi.org/10.1001/jama.219.6.726

24. Musher DM. Editorial commentary: polymerase chain reaction for the tpp 47 gene: a new test for neurosyphilis. Clin Infect Dis [Internet]. 2016 Nov [cited 2020 0ct 15];63(9):1187-8. Available from: https://doi.org/10.1093/cid/ciw518

25. Seña AC, Wolff M, Behets F, Martin DH, Leone P, Langley C, et al. Rate of decline in nontreponemal antibody titers and seroreversion after treatment of early syphilis. Sex Transm Dis [Internet]. 2018 Jan [cited 2020 0ct 15];44(1):6-10. Available from: https:// dx.doi.org/10.1097\%2FOLQ.0000000000000541v

26. Ministério da Saúde (BR). Secretaria de Ciência, Tecnologia e Insumos Estratégicos. Departamento de Assistência Farmacêutica e Insumos Estratégicos. Relação nacional de medicamentos essenciais: RENAME 2017 [Internet]. Brasília: Ministério da Saúde; 2017 [citado 2020 out 15]. 210 p. Disponível em: http://bvsms.saude.gov.br/bvs/publicacoes/relacao_nacional_medicamentos_rename_2017.pdf

27. Conselho Federal de Enfermagem - COFEN (BR). Parecer $n^{0}$ 09/2016/CTAS/COFEN, de 6 de maio de 2016. Solicitação de parecer sobre a administração de medicamentos por via IM em pacientes que usam prótese de silicone [Internet]. Brasília: COFEN; 2016 [citado 2020 out 15]. Disponível em: http://www.cofen. gov.br/parecer-no-092016ctascofen_42147.html

28. Butler T. The jarisch-herxheimer reaction after antibiotic treatment of spirochetal infections: a review of recent cases and our understanding of pathogenesis. Am J Trop Med Hyg [Internet]. 2017 Jan [cited 2020 0ct 15];96(1):46-52. Available from: https://dx.doi.org/10.4269\%2Fajtmh.16-0434

29. Arando M, Fernandez-Naval C, Mota-Foix M, Alvarez A, Armegol P, Barberá MJ. The jarisch-herxheimer reaction in syphilis: could molecular typing help to understand it better? J Eur Acad Dermatol Venereol [Internet]. 2018 0ct [cited 2020 0ct 15];32(10):1791-5. Available from: https://doi.org/10.1111/jdv.15078

30. See S, Scott EK, Levin MW. Penicillin-induced Jarisch-Herxheimer reaction. Ann Pharmacother [Internet].
2005 Dec [cited 2020 0ct 15];39(12):2128-30. Available from: https://doi.org/10.1345/aph.1g308

31. Galvao TF, Silva MT, Serruya SJ, Newman LM, Klausner JD, Pereira MG, et al. Safety of benzathine penicillin for preventing congenital syphilis: a systematic review. PLoS One [Internet]. 2013 [cited 2020 May 20];8(2). Available from: https://dx.doi. org/10.1371\%2Fjournal.pone.0056463

32. Ministério da Saúde (BR). Secretaria de Atenção à Saúde. Departamento de Atenção Básica. Acolhimento à demanda espontânea: queixas mais comuns na Atenção Básica [Internet]. Brasília: Ministério da Saúde; 2013 [citado 2020 out 15]. (Cadernos de Atenção Básica, n. 28, v. II.). Disponível em: https:// aps.saude.gov.br/biblioteca/visualizar/MTIwNA==

33. Conselho Federal de Enfermagem - COFEN (BR). Decisão n ${ }^{0}$ 0094/2015, de 8 de julho de 2015. Revoga o Parecer de Conselheiro 008/2014. PAD COFEN 032/2012. Administração de penicilina pelos profissionais de enfermagem [Internet]. Brasília: COFEN; 2015 [citado 2020 out 15]. Disponível em: http://www.cofen.gov.br/decisao-cofen-no-00942015_32935.html?undefined=undefined

34. Conselho Federal de Enfermagem - COFEN (BR). Nota Técnica COFEN/CTLN n ${ }^{\circ}$ 03/2017, de 14 de junho de 2017. Esclarecimento aos profissionais de enfermagem sobre a importância da administração da Penicilina Benzatina nas Unidades Básicas de Saúde (UBS) do Sistema Único de Saúde (SUS) [Internet]. Brasília: Ministério da Saúde; 2017 [citado 2020 out 15]. Disponível em: http:// www.cofen.gov.br/wp-content/uploads/2017/06/ NOTA-TÉCNICA-COFEN-CTLN-Nº-03-2017.pdfv

35. Solensky R. Allergy to ß-lactam antibiotics. J Allergy Clin Immunol [Internet]. 2012 Dec [cited 2020 0ct 15];130(6):1442-2.e5. Available from: https://doi.org/10.1016/j.jaci.2012.08.021

36. Shenoy ES, Macy E, Rowe T, Blumenthal KG. Evaluation and management of penicillin allergy: a review. JAMA [Internet]. 2019 Jan [cited 2020 0ct 15];321(2):188-99. Available from: https://doi.org/10.1001/jama.2018.19283

37. Romanowski B, Sutherland R, Fick GH, Mooney D, Love EJ. Serologic response to treatment of infectious syphilis. Ann Intern Med [Internet]. 1991 Jun [cited 2020 0ct 15];114(12):1005-9. Available from: https://doi.org/10.7326/0003-4819-114-12-1005 
38. Tong ML, Lin LR, Liu GL, Zhang HL, Zeng YL, Zheng WH, et al. Factors associated with serological cure and the serofast state of HIV-negative patients with primary, secondary, latent, and tertiary syphilis. PLoS One [Internet]. $2013 \mathrm{Jul}$ [cited 2020 0ct 15];8(7):e70102. Available from: https://doi.org/10.1371/journal.pone.0070102

39. Clement ME, Okeke NL, Hicks CB. Treatment of syphilis. JAMA [Internet]. 2014 Nov [cited 2020 May 30];312(18):1905-17. Available from: https://doi.org/10.1001/jama.2014.13259

40. Zhang RL, Wang QQ, Zhang JP, Yang LJ. Molecular subtyping of Treponema pallidum and associated factors of serofast status in early syphilis patients: Identified novel genotype and cytokine marker. PLoS One [Internet]. 2017 Apr [cited 2020 0ct 15];12(4):e0175477. Available from: https:// doi.org/10.1371/journal.pone.0175477

41. Marra CM, Maxwell CL, Tantalo LC, Sahi SK, Lukehart SA. Normalization of serum rapid plasma reagin titer predicts normalization of cerebrospinal fluid and clinical abnormalities after treatment of neurosyphilis. Clin Infect Dis [Internet]. 2008 Oct [cited 2020 0ct 15];47(7):893-9. Available from: https://doi.org/10.1086/591534

42. Brasil. Ministério da Saúde. Portaria de Consolidação $\mathrm{MS} / \mathrm{GM} \mathrm{n}^{\circ}$ 4, de 28 de setembro de 2017. Consolidação das normas sobre os sistemas e os subsistemas do Sistema Único de Saúde [Internet]. Diário Oficial da União, Brasília (DF), 2017 out 3 [citado 2020 out 15];Seção 1:288. Disponível em: http://bvsms.saude.gov.br/bvs/ saudelegis/gm/2017/prc0004_03_10_2017.html

43. Brasil. Presidência da República. Lei n ${ }^{0} 6.259$, de 30 de outubro de 1975. Dispõe sobre a organização das ações de Vigilância Epidemiológica, sobre 0 Programa Nacional de Imunizações, estabelece normas relativas a notificação compulsória de doenças, e dá outras providências [Internet]. Diário Oficial da União, Brasília (DF), 1975 out 31 [citado 2020 out 15];Seção 1:14433. Disponível em: http:// www.planalto.gov.br/ccivil_03/leis/16259.htm
44. Schober PC, Gabriel G, White P, Felton WF, Thin RN. How infectious is syphilis? Br J Vener Dis [Internet]. 1983 Aug [cited 2020 0ct 15];59(4):217-219. Available from: http://dx.doi.org/10.1136/sti.59.4.217

45. Janier M, Hegyi V, Dupin N, Unemo M, Tiplica GS, Potočnik M, et al. 2014 European guideline on the management of syphilis. J Eur Acad Dermatol Venereol [Internet]. 2014 Dec [cited 2020 0ct 15];28(12):158193. Available from: https://doi.org/10.1111/jdv.12734

46. Ministério da Saúde (BR). Secretaria de Vigilância em Saúde. Departamento de Doenças de Condições Crônicas e Infecções Sexualmente Transmissíveis. Protocolo clínico e diretrizes terapêuticas para prevenção da transmissão vertical do HIV, sífilis e hepatites virais [Internet]. Brasília: Ministério da Saúde; 2015 [citado 2020 out 15]. 248 p. Disponível em: http:/www.aids.gov.br/pt-br/pub/2015/ protocolo-clinico-e-diretrizes-terapeuticas-para-prevencao-da-transmissao-vertical-de-hiv

47. Ministério da Saúde (BR). Secretaria de Atenção à Saúde. Departamento de Ações Programáticas Estratégicas. Coordenação Nacional de Saúde do Homem. Guia do pré-natal do parceiro para profissionais de saúde [Internet]. Brasília: Ministério da Saúde; 2016 [citado 2020 out 15]. 55 p. Disponível em: https://portalarquivos2.saude.gov.br/ images/pdf/2016/agosto/11/guia_PreNatal.pdf

48. Hutchinson CM, Hook EW III, Shepherd M, Verley J, Rompalo AM. Altered clinical presentations and manifestations of early syphilis in patients with human immunodeficiency vírus infection. Ann Intern Med [Internet]. 1994 Jul [cited 2020 0ct 15];121(2):94-9. Available from: https://doi. org/10.7326/0003-4819-121-2-199407150-00003

49. Rolfs RT, Joesoef MR, Hendershot EF, Rompalo AM, Augenbraun MH, Chiu M, et al. The syphilis and HIV Study Group. A randomized trial of enhanced therapy for early syphilis in patients with and without human immunodeficiency virus infection. N Engl J Med [Internet]. 1997 Jul [cited 2020 Oct 15];337(5):307-14. Available from: https:// doi.org/10.1056/nejm199707313370504 


\section{Abstract}

The Clinical Protocol and Therapeutic Guidelines for Comprehensive Care for People with Sexually Transmitted Infections, published by the Ministry of Health of Brazil in 2020, includes the update on acquired syphilis. The document comprises rapid tests use, safety and efficacy of the administration of benzathine benzylpenicillin, follow-up of cases, clinical and laboratory management of neurosyphilis, approach to sexual partnerships, assistance and monitoring of diagnosed pregnant women, and specificities of syphilis and HIV co-infection, as well as a summary of the notification of cases. It is necessary to train bealth managers and professionals on a continuous basis, with a view to integrating care and surveillance, strengthening effective syphilis control actions, increasing the search for sexual partnerships, and expanding the access of the most vulnerable populations to bealth services.

Keywords: Syphilis; Clinical Protocols; Diagnosis; Therapeutics.

\section{Resumen}

El Protocolo Clínico y Directrices Terapéuticas para la atención integral a las personas con infecciones de transmisión sexual, publicado por el Ministerio de Salud de Brasil en 2020, incluye la actualización sobre la sifilis adquirida. El documento comprende las pruebas rápidas, la seguridad y eficacia de la administración de bencilpenicilina benzatínica, el seguimiento de casos, el manejo clínico y de laboratorio de la neurosífilis, el enfoque de las parejas sexuales, la asistencia $y$ seguimiento de embarazadas diagnosticadas y las especificidades de la coinfección sífilis y VIH, así como un resumen de la notificación de casos. Es necesario capacitar a los gerentes y profesionales de la salud de manera continua, con miras a integrar la atención y la vigilancia, fortalecer las acciones efectivas de control de la sifilis, expandir la búsqueda de las parejas sexuales y ampliar el acceso de las poblaciones más vulnerables a los servicios de salud.

Palabras clave: Sífilis; Protocolos Clínicos; Diagnóstico; Terapéutica.

Recebido em 28/07/2020

Aprovado em 23/09/2020

Editora associada: Taís Freire Galvão - ำ orcid.org/0000-0003-2072-4834 


\section{Errata}

No artigo "Protocolo Brasileiro para Infecções Sexualmente Transmissíveis 2020: sífilis adquirida", doi: 10.1590/\$1679-4974202100004.esp1, Figura 2 - Testes imunológicos para diagnóstico de sífilis e Figura 3 - Resultados de testes treponêmicos e não treponêmicos, interpretação e conduta, publicado no periódico Epidemiologia e Serviços de Saúde, v. 30(Esp.1):1-12, nas páginas 4 e 5 :

Figura 2 - Testes imunológicos para diagnóstico de sífilis

Onde se lia:

\begin{tabular}{|c|c|c|}
\hline Testes imunológicos & Tipos & Observações \\
\hline \multirow{4}{*}{ Treponêmicos } & Teste rápido (ex.: imunocromatográficos) & São os primeiros a se tornar reagentes. \\
\hline & $\begin{array}{l}\text { Teste de imunofluorescência indireta - fluorescent } \\
\text { treponemal antibody-absorption (FTA-Abs) }\end{array}$ & $\begin{array}{l}\text { Permanecem reagentes na maioria dos casos de } \\
\text { sífilis durante toda a vida, independentemente do } \\
\text { tratamento. }\end{array}$ \\
\hline & $\begin{array}{l}\text { Ensaios imunoenzimáticos - enzyme-linked } \\
\text { immunossorbent assay (ELISA) e suas variações, como } \\
\text { os ensaios de quimioluminescência }\end{array}$ & $\begin{array}{l}\text { São importantes para diagnóstico, mas não estão } \\
\text { indicados para o monitoramento da resposta ao } \\
\text { tratamento. }\end{array}$ \\
\hline & $\begin{array}{l}\text { Testes de hemaglutinação - Treponema Pallidum } \\
\text { Haemagglutination Test (TPHA) e de aglutinação de } \\
\text { partículas - T. pallidum particle agglutination assay } \\
\text { (TPPA); ensaios de micro-hemaglutinação - micro- } \\
\text { haemagglutination assay (MHA-TP) }\end{array}$ & \\
\hline \multirow{4}{*}{ Não treponêmicos } & Venereal disease research laboratory (VDRL) & $\begin{array}{l}\text { Tornam-se reagentes cerca de uma a três semanas } \\
\text { após o aparecimento do cancro duro. }\end{array}$ \\
\hline & Rapid plasma reagin (RPR) & \multirow{2}{*}{$\begin{array}{l}0 \text { resultado final desses testes reagentes deve ser } \\
\text { expresso em títulos, conforme a última diluição que } \\
\text { apresentar reatividade (1:2, 1:4, 1:8 etc.). }\end{array}$} \\
\hline & Toluidine red unheated serum test (TRUST) & \\
\hline & Unheated-serum reagin (USR) & $\begin{array}{l}\text { São importantes para diagnóstico e monitoramento } \\
\text { da resposta ao tratamento. }\end{array}$ \\
\hline
\end{tabular}

Leia-se:

\begin{tabular}{|l|l|l|}
\hline Testes imunológicos & Tipos & Observações \\
\hline \multirow{5}{*}{ Treponêmicos } & Teste rápido (ex.: imunocromatográficos) & São os primeiros a se tornarem reagentes. \\
\cline { 2 - 2 } & $\begin{array}{l}\text { Teste de imunofluorescência indireta - fluorescent } \\
\text { treponemal antibody-absorption (FTA-Abs) }\end{array}$ & $\begin{array}{l}\text { Permanecem reagentes na maioria dos casos de sífilis } \\
\text { durante toda a vida, independentemente do tratamento. }\end{array}$ \\
\cline { 1 - 2 } & $\begin{array}{l}\text { Ensaios imunoenzimáticos - enzyme-linked } \\
\text { immunossorbent assay (ELISA) e suas variações, como importantes para diagnóstico, mas não estão } \\
\text { os ensaios de quimioluminescência }\end{array}$ & $\begin{array}{l}\text { indicados para o monitoramento da resposta ao } \\
\text { tratamento. }\end{array}$ \\
\cline { 1 - 2 } & $\begin{array}{l}\text { Testes de hemaglutinação - Treponema Pallidum } \\
\text { Haemagglutination Test (TPHA) e de aglutinação de } \\
\text { partículas - T.pallidum particle agglutination assay } \\
\text { (TPPA); ensaios de micro-hemaglutinação - micro- } \\
\text { haemagglutination assay (MHA-TP) }\end{array}$ & \\
\hline
\end{tabular}


Continuação

\begin{tabular}{|c|c|c|}
\hline Testes imunológicos & Tipos & Observações \\
\hline \multirow{4}{*}{ Não treponêmicos } & Venereal disease research laboratory (VDRL) & $\begin{array}{l}\text { Tornam-se reagentes cerca de uma a três semanas após o } \\
\text { aparecimento do cancro duro. }\end{array}$ \\
\hline & Rapid plasma reagin (RPR) & \multirow{2}{*}{$\begin{array}{l}0 \text { resultado final desses testes reagentes deve ser expresso } \\
\text { em títulos, conforme a última diluição que apresentar } \\
\text { reatividade (1:2, 1:4, 1:8 etc.). }\end{array}$} \\
\hline & Toluidine red unheated serum test (TRUST) & \\
\hline & Unheated-serum reagin (USR) & $\begin{array}{l}\text { São importantes para diagnóstico e monitoramento da } \\
\text { resposta ao tratamento. }\end{array}$ \\
\hline
\end{tabular}

Figura 3 - Resultados de testes treponêmicos e não treponêmicos, interpretação e conduta

Onde se lia:

\begin{tabular}{|c|c|c|c|}
\hline $\begin{array}{l}\text { Primeiro teste }{ }^{\mathrm{a}}+\text { teste } \\
\text { complementar }\end{array}$ & \multicolumn{2}{|l|}{ Possíveis interpretações } & Conduta \\
\hline \multirow{2}{*}{$\begin{array}{l}\text { Teste treponêmico reagente + teste } \\
\text { não treponêmico reagente ou Teste } \\
\text { não treponêmico reagente + teste } \\
\text { treponêmico reagente }\end{array}$} & - Diagnóstico de sífilis & $\begin{array}{l}\text { - Classificação do estágio clínico } \\
\text { a ser definida de acordo com o } \\
\text { tempo de infecção e o histórico de } \\
\text { tratamento. }\end{array}$ & $\begin{array}{l}\text { - Quando for sífilis, tratar, realizar } \\
\text { monitoramento com teste não } \\
\text { treponêmico e notificar o caso de sífilis. }\end{array}$ \\
\hline & \multicolumn{2}{|l|}{ - Cicatriz sorológicab } & $\begin{array}{l}\text { - Quando for confirmado caso de cicatriz } \\
\text { sorológica, apenas orientar. }\end{array}$ \\
\hline \multirow{4}{*}{$\begin{array}{l}\text { Teste não treponêmico reagente + } \\
\text { teste treponêmico não reagente ou } \\
\text { Teste treponêmico reagente + teste não } \\
\text { treponêmico não reagente }\end{array}$} & \multirow{2}{*}{$\begin{array}{l}\text { - Realiza-se um terceiro } \\
\text { teste treponêmico com } \\
\text { metodologia diferente do } \\
\text { treponêmico realizado. }\end{array}$} & $\begin{array}{l}\text { - Se reagente: diagnóstico de sífilis } \\
\text { ou cicatriz sorológica. }\end{array}$ & $\begin{array}{l}\text { - Quando for sífilis, tratar, realizar } \\
\text { monitoramento com teste não } \\
\text { treponêmico e notificar o caso de sífilis. }\end{array}$ \\
\hline & & $\begin{array}{l}\text { - Se não reagente: considera-se } \\
\text { resultado falso reagente para o } \\
\text { primeiro teste, sendo excluído } 0 \\
\text { diagnóstico de sífilis. }\end{array}$ & $\begin{array}{l}\text { - Quando for confirmado caso de cicatriz } \\
\text { sorológica, apenas orientar. }\end{array}$ \\
\hline & \multicolumn{2}{|c|}{$\begin{array}{l}\text { - Se o terceiro teste treponêmico não estiver disponível, avaliar } \\
\text { exposição de risco, sinais e sintomas e histórico de tratamento para } \\
\text { definiçã̃o de conduta. }\end{array}$} & $\begin{array}{l}\text { - Para os casos concluídos como } \\
\text { ausência de sífilis, apenas orientar. }\end{array}$ \\
\hline & \multicolumn{3}{|l|}{ - Cicatriz sorológicab } \\
\hline \multirow{2}{*}{$\begin{array}{l}\text { Teste não treponêmico ou treponêmico } \\
\text { não reagente + não realizar teste } \\
\text { complementar se o primeiro teste for } \\
\text { não reagente e se não houver suspeita } \\
\text { clínica de sífilis primária }\end{array}$} & \multirow{2}{*}{\multicolumn{2}{|c|}{$\begin{array}{l}\text { - Ausência de infecção ou período de janela } \\
\text { imunológica' de sífilis recente. }\end{array}$}} & $\begin{array}{l}\text { - Em caso de suspeita clínica e/ou } \\
\text { epidemiológica, solicitar nova coleta de } \\
\text { amostra em } 30 \text { dias. }\end{array}$ \\
\hline & & & $\begin{array}{l}\text { - Evitar retardar a instituição do } \\
\text { tratamento, caso o diagnóstico de sífilis } \\
\text { seja o mais provável (ex.: visualização } \\
\text { de úlcera anogenital) ou o retorno da } \\
\text { pessoa ao serviço de saúde não possa } \\
\text { ser garantido. }\end{array}$ \\
\hline
\end{tabular}


Leia-se:

\begin{tabular}{|c|c|c|c|}
\hline $\begin{array}{l}\text { Primeiro teste }{ }^{\mathrm{a}}+\text { teste } \\
\text { complementar }\end{array}$ & \multicolumn{2}{|l|}{ Possíveis interpretações } & Conduta \\
\hline \multirow{2}{*}{$\begin{array}{l}\text { Teste treponêmico reagente + teste } \\
\text { não treponêmico reagente ou Teste } \\
\text { não treponêmico reagente + teste } \\
\text { treponêmico reagente }\end{array}$} & - Diagnóstico de sífilis & $\begin{array}{l}\text { - Classificação do estágio clínico a ser } \\
\text { definida de acordo com o tempo de } \\
\text { infecção e o histórico de tratamento. }\end{array}$ & \multirow{6}{*}{$\begin{array}{l}\text { - Quando for sífilis, tratar, realizar } \\
\text { monitoramento com teste não } \\
\text { treponêmico e notificar o caso de } \\
\text { síilis. } \\
\text { - Quando for confirmado caso de } \\
\text { cicatriz sorológica, apenas orientar. } \\
\text { - Para os casos concluídos como } \\
\text { ausência de sífilis, apenas orientar. }\end{array}$} \\
\hline & \multicolumn{2}{|l|}{ - Cicatriz sorológica ${ }^{b}$} & \\
\hline \multirow{4}{*}{$\begin{array}{l}\text { Teste não treponêmico reagente + } \\
\text { teste treponêmico não reagente ou } \\
\text { Teste treponêmico reagente + teste } \\
\text { não treponêmico não reagente }\end{array}$} & \multirow{2}{*}{$\begin{array}{l}\text { - Realiza-se um terceiro } \\
\text { teste treponêmico com } \\
\text { metodologia diferente do } \\
\text { treponêmico realizado. }\end{array}$} & $\begin{array}{l}\text { - Se reagente: diagnóstico de sífilis ou } \\
\text { cicatriz sorológica. }\end{array}$ & \\
\hline & & $\begin{array}{l}\text { - Se não reagente: considera-se } \\
\text { resultado falso reagente para o } \\
\text { primeiro teste, sendo excluído } 0 \\
\text { diagnóstico de sífilis. }\end{array}$ & \\
\hline & \multicolumn{2}{|c|}{$\begin{array}{l}\text { - Se o terceiro teste treponêmico não estiver disponível, avaliar } \\
\text { exposição de risco, sinais e sintomas e histórico de tratamento para } \\
\text { definição de conduta. }\end{array}$} & \\
\hline & \multicolumn{2}{|l|}{ - Cicatriz sorológicab } & \\
\hline $\begin{array}{l}\text { Teste não treponêmico ou treponêmico } \\
\text { não reagente + não realizar teste } \\
\text { complementar se o primeiro teste for } \\
\text { não reagente e se não houver suspeita } \\
\text { clínica de sífilis primária }\end{array}$ & \multicolumn{2}{|c|}{$\begin{array}{l}\text { - Ausência de infecção ou período de janela } \\
\text { imunológica' de sífilis recente. }\end{array}$} & $\begin{array}{l}\text { - Em caso de suspeita clínica e/ou } \\
\text { epidemiológica, solicitar nova coleta } \\
\text { de amostra em } 30 \text { dias. } \\
\text { - Evitar retardar a instituição do } \\
\text { tratamento, caso o diagnóstico } \\
\text { de sífilis seja o mais provável (ex.: } \\
\text { visualização de úlcera anogenital) ou o } \\
\text { retorno da pessoa ao serviço de saúde } \\
\text { não possa ser garantido. }\end{array}$ \\
\hline
\end{tabular}

